\title{
Developing Communication and Organization Skills: The ELITE Life Skills Reflective Practice Intervention
}

\author{
Martin lan Jones \\ University of Gloucestershire \\ David Lavallee and David Tod \\ Aberystwyth University
}

\begin{abstract}
The aim of the current study was to evaluate the ELITE intervention as a method of increasing the perceived use of communication and organization skills in young people. The participants were three male field hockey players and two female tennis players from a British university. We used a series of single subject, multiple baselines, with minimal meaningful harm and benefit criteria and $\mathrm{SMD}_{\text {all }}$ effect sizes to evaluate the ELITE intervention. The results revealed no meaningful harm from participating in the program, and the tennis players showed meaningful benefits. $\mathrm{SMD}_{\text {all }}$ effect sizes all demonstrated that the intervention had a positive effect. Post intervention interviews indicated that participants valued the targeted life skills, and the program was enjoyable. Implications of this study suggest that scholars and practitioners can use the ELITE intervention to increase life skills in young people.
\end{abstract}

During a speech to the International Olympic Committee (IOC) Jacques Rogge (2004), the president of the IOC at the time of this study, stated, "The world of sport is not separate from the rest of the world. Sport breaks down barriers, promotes self-esteem, and can teach life skills and healthy behavior." This quote demonstrates a widely held belief that sport has the ability to teach young people positive life skills. Despite this belief, studies investigating the development of life skills through of sport are limited. Gould and Carson (2008, p 71) stated, "It is especially important that life skill development through sport evaluation research be conducted. ... Claiming sport builds character is not enough-program organizers must now demonstrate it."

Existing life skills research has focused on the period of adolescence. Contemporary "adolescents", who remain in full time education, remain out of the labor market, remain financially dependent on parents, do not begin capital accumulation, and do not acquire adult roles in society until early- to mid-twenties (Coleman \&

Jones is with the Faculty of Applied Sciences, University of Gloucestershire, Gloucester, UK. Lavallee and Tod are with the Dept. of Sport and Exercise Science, Aberystwyth University, Aberystwyth, UK. 
Roker, 1998). As such, contemporary adolescence is a longer transitional period than it used to be. Adolescence appears to be age related but not age dependent (i.e., adolescents may be over 20 years of age). Arnett (2007) stated that in the past five decades, the lives of young people have changed so dramatically scholars have labeled a new period of the life course. For most people, "emerging adulthood" lasts from the late teens until the late twenties and is increasingly important as a time for identity exploration, exploration of educational and occupational paths, frequent changes in direction (in terms of romantic partnerships, occupations, education, and geographical location), and self-focus (i.e., before life is structured by institutional demands and obligations). Because of changes in adolescence, and the potential importance of emerging adulthood, the United Nations (2005) do not use adolescence as a term to classify individuals in this transitional stage of life. Rather, they use the terms youth and young people, to represent individuals who are aged between 15-24 years and 10-24 years respectively. The research participants in the current study are all young people.

In the United Kingdom, Fox and Rickards (2004) conducted the Sport and Leisure General Household Survey with around 14,800 people aged 16 years and over. Results revealed that $72 \%$ of young people aged between 16-19 years of age and $61 \%$ of young people aged between 20-24 years of age participated in sports, games, and physical activities (excluding walking). Furthermore, 33\% of 16-19 years olds and $32 \%$ of 20-24 year olds had been members of sports clubs, and $42 \%$ of 16-19 year olds and 3\% of 20-24 year old had participated in competitive sport in the 12 months before the research. This research supports Brunelle, Danish, and Forneris's (2007) contention that adolescents will be participating in sports regardless of its prosocial value, and scholars and practitioners should explore sport as a context for life skills development.

There are few evaluations of life skills interventions in a sporting context, and researchers need to conduct more evaluations of sport based life skills programs. The few existing evaluations (e.g., Brunelle, Danish, \& Forneris, 2007; Papacharisis, Goudas, Danish, \& Theodorakis, 2005) have demonstrated that sport based life skills programs can be used to develop specific life skills (e.g., goal setting, problem solving, and overcoming obstacles). However, existing sport based life skills programs typically have targeted younger adolescents and have used abbreviated versions of the same Sports United to Promote Education and Recreation life skills program (SUPER: Danish, 2002).

The SUPER program uses goal setting as the foundational life skill to teach problem solving and overcoming obstacles to goal achievement. SUPER is taught as a series of 18 sports clinics with participants involved in three sets of activities; namely, learning the physical skills related to a specific sport, learning life skills related to sports in general, and playing the sport. Program leaders teach the life skills component using a players' workbook that requires participants to fill in worksheets related to the targeted life skills. To date, researchers and practitioners have not widely used the SUPER program to teach other potentially pertinent life skills to young people. Subsequently, scholars and practitioners could develop other life skills programs to augment the SUPER program.

Danish, Petitpas, and Hale (1993) stated that one of the barriers to life skill development might be that athletes are not aware of the skills they have learned. Young people could develop and transfer life skills to other life domains if they 
increase their awareness of the skills they acquired through sport, increase their awareness of knowledge of how and in what context they learned life skills, and increase their awareness that skills are valued in other life domains (Danish et al., 1993). Researchers have also identified self-awareness as a crucial developmental outcome for all youth development programs, not just sport. Specifically, the Collaborative for Academic, Social, and Emotional Learning (CASEL; 2003) identified a core set of competencies that provide a foundation for effective development including (but not limited to) self-awareness and social awareness. CASEL defined self-awareness as knowing what we are feeling and thinking, having a realistic assessment of our own abilities, and a well-grounded sense of self-confidence. It may be the realistic assessment of ability combined with self-confidence facilitates transfer.

Schön (1987) presented a theory of reflective practice as a method of learning that emphasized examining our experiences and connecting with our feelings. Schön's theory suggested people learn in two different ways know as reflection in action and reflection on action. Firstly, people gain knowledge through reflection in action. Reflection in action ("thinking on your feet") involves developing new understandings to inform actions in the situation that is unfolding. Schön suggested that when individuals go about the spontaneous performance of actions of everyday life they demonstrate specific knowledge. However, often people cannot articulate this knowledge. Individuals cannot say what they know; instead, they do what they know (i.e., knowledge is in action). For example, children will be able coordinate the multiple bodily movements involved in throwing a ball and judge the distance of a target; however, it is unlikely that they would be able to articulate how they coordinated bodily movements to throw the ball without guided reflection to help them understand what they have done. Similarly, people might learn life skills by being in a structured sporting environment and by interacting with peers, coaches, and parents, but they may not be able to articulate which skills they learned or how they learned them without help. To highlight what people learn in practice, and to prevent individuals becoming narrow and repetitive, people need to employ another type of reflection. People can use reflection on action to explore why they acted as they did, what was happening in a situation (and why), what they have learned, and how they can use this knowledge in the future. The outcome of reflection on action is a repertoire of thoughts and ideas based on successful response strategies and outcomes that one can draw upon when confronted with new scenarios. The familiar experience (e.g., sport) functions as a precedent, a metaphor, or an exemplar for the unfamiliar one (e.g., new sporting scenarios and nonsport life domains) allowing one to function when in unfamiliar settings (Schön). For example, a football player may practice skills to manage prematch nerves; and via reflective practice, then recognizes the need to use those skills to manage the nerves before an exam.

Sport provides young people with a range of developmental experiences including interacting with key social agents over prolonged periods, participating within a rule-bound environment, and participating with free choice (Larson, 2000) that may result in life skill learning. However, young people may not understand, or believe, that they possess these skills. As such, reflective practice is needed to increases participant awareness of the requirements of the sporting context (e.g., needing to negotiate training and work schedules with coaches and academic staff). The skills that participants had already previously used were the focus of the ELITE intervention. By helping young people understand and become more 
aware of having used skills in the past, we hypothesized that they will increase their perceived use of these skills.

We developed the Enhancement of Leadership Intercommunication Teamwork and Excellence (ELITE) intervention as a method of increasing perceived use of life skills through reflective practice. We developed the ELITE intervention as an eightweek intervention that aimed to increase participants' self-awareness of perceived use of life skills. Based on the results of Jones and Lavallee (2009) we decided to target communication skills and organization skills. Jones and Lavallee conducted a series of focus groups with athletes (aged 15-22 years), coaches, and experts in youth sport and sport psychology. The participants in the Jones and Lavallee study believed that communication and organization skills were the most important life skills for British adolescent athletes to learn. Jones and Lavallee described communication skills and organization skills as umbrella terms for groups of life skills. These skills are examples of two groups of skills that young people could learn through sport. Communication and organization are not umbrella terms for all the skills that young people could learn through sport or are worthwhile for young sports people to learn. Research has also shown these skills to be important for positive development (e.g., Dworkin, Larson, \& Hansen, 2003; Hansen, Larson, \& Dworkin, 2003; Larson, 2000; Larson, Hansen, \& Moneta, 2006; National Center for Chronic Disease Prevention and Health Promotion, 2007).

We defined communication skills as ranges of skills to enable the use of language and behavior to convey and receive information. Examples of communication skills, taken from Jones and Lavallee (2009), included verbal communication skills and listening skills. We defined organizational skills as the skills needed to manage the self effectively so that one can have a normal course of living while averting problems caused by disorganization. The organizational skills described by Jones and Lavallee specifically relate to self-organization. For example, time management, personal planning, prioritizing, and setting goals.

Communication skills are essential skills for young people to learn. Young people need communication skills to demonstrate refusal, for negotiation, and for collaboration. Young people need communication skills to demonstrate strategies to prevent, manage, or resolve interpersonal conflicts without harming the self or others. Finally, young people need communication skills to ask for and offer assistance to enhance the health of the self and others (National Center for Chronic Disease Prevention and Health Promotion, 2007).

Scholars and practitioners have also indentified organizational skills as crucial youth development outcomes. For example, Larson and his colleagues (Dworkin et al. 2003; Hansen, et al., 2003; Larson, 2000; Larson et al., 2006) identified initiative as a crucial positive youth development outcome that would benefit the lives of young people. Larson stated initiative comprises the ability to be motivated from within, to direct attention and effort toward a challenging goal. In addition, Larson also discussed initiative in relation to the ability to plan personal effort over time and to manage one's own attention and activities. In addition to being an important quality in its own right, Larson stated that initiative is a core requirement for other components of positive development such as creativity, leadership, altruism, and civic engagement.

We implemented the ELITE program was across two phases. The first phase targeted communication skills, and the second phase targeted organization skills. 
Each phase comprised four 1-hr sessions delivered over four consecutive weeks. Before the sessions began, the first author met with the participants to collect baseline data when we gave no treatment. During the final week of baseline, we invited the participants to attend a presentation outlining the intervention procedures. The first author told the participants what to expect over the next eight weeks, and the first author gave participants a copy of their reflection journal so that participants could familiarize themselves with the procedures. The journal included week-by-week instructions, specified the learning objectives, predicted length of the session, explanations of key terms, key teaching points, equipment lists, progressions if participants chose to work on their life skills between sessions, and spaces to make notes.

The first session involved reflecting on life skills practiced in the context of training by answering a series of questions. For example, "describe the communication / organization skills you used in your last training session". The second session progressed by focusing on life skills practiced in competition. For example, "describe a match, competition or tournament in which communication / organization skills helped your performance". The third session advanced into anticipatory reflection (i.e., planning). For example, questions included, "which scenarios in the future do you anticipate you will need good communication / organization skills"? During the third session, the first author actively encouraged the participants to think about nonsport scenarios that would also require good communication / organization skills, and to think about how principles of good sport communication / organization applied to these nonsport scenarios. The fourth session gave participants the opportunity to practice the skills they had been discussing in the previous weeks (i.e., reflecting in action). The participants put the principles of effective communication / organization into practice in a series of interactive games and activities that required the participants to use the skills they had previously discussed. For example, when practicing communication skills participants we gave the participants team-building activities that required clear communication to accomplish the task. Similarly, when practicing organization skills we asked participants to pattern, prioritize, and plan (Petrie, \& Denson, 1999) their academic and training commitments to produce a study timetable for a forthcoming exam period. We did not provide participants with suggestions about how to complete the tasks; we just issued procedural instructions. As such, participants chose to use skills that they discussed in previous sessions. All reflection questions were relevant to the athlete's entire sporting experience, not just training and competition. It is not clear whether participants reflected on their most proximal experiences, as we did not measure this. By not limiting reflections to athletes' most recent experiences, we believed that athletes were able to draw on a larger repertoire of experiences.

We carried out all of the sessions in changing rooms, on training pitches / courts, on benches at the courtside, and in meeting rooms. We also convened sessions at the behest of the head coaches and were typically in the hour before training started. During the sessions, the participants sat in small groups and discussed the questions among each other. Participants also made notes, drew diagrams, and conversed to stimulate reflection.

The aim of the current study was to evaluate the ELITE life skills reflective practice intervention as a method of increasing the perceived use of communication and organization skills in young people. We hypothesized that the participants 
would increase perceived use of communication and organization skills. The use of reflective practice to develop perceived use of life skills could contribute to the literature by supporting existing use of reflective practice (e.g., in the personal-social responsibility model: Hellison, 1978) and by highlighting alternative approaches to augment other types of life skills education (e.g., SUPER).

\section{Method}

\section{Participants}

Upon receiving Research Ethics Committee approval, we approached full-time head coaches $(n=8)$ at a British University. We approached a diversity of sports to find athletes with a range of training and competition experiences. This university had long been recognized, nationally and internationally, for its development of sporting excellence. All of the athletes in the study had represented their counties at the senior level, and several hockey players had also represented their home country at junior and senior international levels. In addition to sporting excellence, this university had recently entered the top 15 of universities in the UK and had an average entrance AS/A level score of 183 points (of a possible maximum score of 250 points). Of all the coaches approached at the university, only the coaches from tennis and hockey agreed to participate. With the coaches' permission, we invited 22 individuals at normal practice sessions, and explained that participation was voluntary, they were free to withdraw, and nonparticipation would have no negative consequences. Of those approached, 15 agreed to participate (response rate of $68 \%$ ). Of the fifteen who initially agreed to take part in the study, ten participants were unable to complete the intervention because of other academic and sporting commitments and we do not present their data. The participants who dropped out could not attend training sessions because they were away from the university at training camps for other teams, or they stopped attending training because of increased academic commitments. Given that the participants were no longer attending the training sessions, we concluded that the drop out was not solely due to lack of interest or motivation in completing the ELITE intervention. In sum, three male field hockey players and two female tennis players made up the sample (response rate of 23\%). Participant tennis one was 19 years and 6 months, and she had been playing tennis for 15 years. Participant tennis two was 20 years and 8 months old, and she had been playing tennis for 15 years. Participant hockey one was 19 years old, and he had been playing hockey for 12 years. Participant hockey two was 19 years and one month old, and he had been playing hockey for 5 years. Participant hockey three was 18 years old, and he had been playing hockey for 13 years. All participants were training and competing throughout the intervention. No participants had previous experience of life skill programs or working with a sport psychologist. We did not record the coaching styles and practices of the coaches, so it is not clear whether coaches modeled good life skills.

\section{Design}

We employed a series of single subject, multiple baselines, with minimal meaningful harm and benefit criteria and $\mathrm{SMD}_{\text {all }}$ effect sizes to evaluate the ELITE 
intervention. With a multiple baseline across behaviors design researchers apply the same treatment sequentially to separate and independent target behaviors in a single subject (Barlow \& Hersen, 1984). In the current study, we introduced the first target behavior (communication) followed by the second targeted behavior (organization). We delivered the intervention in a group setting that occasionally required the participants to work together on tasks. Although this may suggest that the group was the unit of analysis (rather the individual) we have presented individual data because reflection is ultimately an intraindividual skill.

\section{Measures}

The research team developed a 28 -item life skills instrument to evaluate participants' perceived use of communication and organization skills. We created items based on an extensive review of life skills and positive youth development literature (e.g., Hansen \& Larson, 2005; Jones \& Lavallee, 2009). We structured the items with the stem "Based on your involvement in sport please rate whether you have had the following experiences. Place an $\mathrm{x}$ in the box to show much you agree with the statement". We did not negatively word any items, but we did instruct the participants that there were no right or wrong answers and it was important to be as honest as possible. Examples of questions used to measure communication and organization skills included, "I learned about the importance of communication," "I became better at communicating with people outside of sport," "I became better at managing my time," "I learned about setting priorities," and "I learned about why planning is important in other areas of my life." We scored the items with a visual analog scale and then converted responses to a 10-point Likert score by assigning a number (1-10) dependent on the position of the participants' mark along the scale. To ensure content and face validity, a group of graduate students, the second author, and faculty staff reviewed all items. We considered these individuals suitable examiners of the new items based on their experience conducting research in sport psychology and youth sport, and their practical sport psychology and coaching experiences. We then piloted the completed version with 18 university athletes. No athletes requested clarification of items, and we did not reject any items. The communication subscale had a Cronbach's $\mathrm{a}=.87$, and the organization subscale had a Cronbach's a $=.91$ Readers may request a copy of the 28 -item life skills instrument and additional principal components analysis statistics from the first author.

Self-report data may be construed as limiting given the fact that knowledge in action is noncognitive knowing (Van Manen, 1999) and cannot be measured with self-reports. However, we believe that the process of reflection transforms noncognitive knowing (i.e., knowledge in action) into conscious understanding of skills practiced that researchers can measure with self-report. As such, the 28-item measure is not measuring knowledge in action but rather the self-awareness developed.

Social validation interviews evaluated the practical and applied importance of the intervention. Wolf (1978) suggested researchers could establish social validity by examining the extent to which the dependent variables (communication and organization skills) were important to the participant, by assessing whether the intervention procedures used were acceptable to participants, and by determining whether the participants were satisfied with the results. These questions formed an interview guide for interviews held after the intervention. 


\section{Procedure}

We incorporated the experimental procedures into participants' normal training and competition schedules. The participants took part in one session per week, and the sessions took place immediately before training sessions. The participants completed the 28-item measure immediately after the one-hour intervention sessions had finished. The first author invited squad members who were not participating in the research to participate in sessions at their discretion. The first author collected baseline, intervention, and social validity data over a period of 17 weeks with two separate groups (i.e., tennis and field hockey). Baseline lasted seven weeks, the communication phase lasted for four weeks, and the organization phase lasted for four weeks. Finally, the first author collected data for two weeks after the intervention had finished. We wrote up all the procedures in a workshop leader's manual and participant workbook. Readers can request a copy of the participants' workbook and leader's manual from the first author.

\section{Treatment of the Data}

We plotted the participants' scores for baseline, communication intervention, organization intervention, and post intervention phases on a graph (See Figures 1 and 2). We then subjected the data to a visual inspection to identify whether an effect occurred. We used the following criteria to evaluate whether the intervention had an effect. First, the baseline had to be either stable (i.e., horizontal), or in an opposite direction to that predicted for the treatment. Second, we had to observe an effect with few overlapping data points between baseline and treatment phases. Third, we had to observe an effect soon after the introduction of treatment (Johnson, Hrycaiko, Johnson, \& Halas, 2004). In addition to the established criteria for assessing single subject research, we also implemented criteria for a minimal meaningful harm and minimal meaningful benefit (Stoové \& Andersen, 2003), to identify whether observed changes are meaningful, and effect size calculations of single subject data known as Standard Mean Difference $\left(\mathrm{SMD}_{\mathrm{all}}\right.$ : Olive \& Smith, 2005).

Stoové and Andersen (2003) stated that it is important to establish meaningful changes (not just statistically significant changes) to augment the interpretation of the results. Indicating what levels of change are harmful or beneficial to the participants will help support the usefulness of an intervention from a practical perspective and add some context to aid the interpretation of the single subject graphs. Minimal meaningful harm was set at the lowest baseline score (i.e., reported life skills do not decrease because of the intervention). The minimal meaningful benefit was harder to predict because researchers base the determination of the minimal meaningful benefit on knowledge of the field, knowledge of the variables, and knowledge of the potential changes possible with the specific population one is studying (Stoové \& Andersen). No previous research has studied this population using measures of communication or organization before; therefore, we decided not to specify a minimal meaningful benefit until we had collected baseline data.

Olive and Smith (2005) stated, although single subject researchers typically do not include statistics to support conclusions for intervention effectiveness it is 
becoming more important to supplement visual analysis with effect sizes. Several methods of measuring effect size exist, and Olive and Smith recommend using Standard Mean Difference $\left(\mathrm{SMD}_{\mathrm{all}}\right)$. This method utilizes data from the mean performance during baseline as well as mean performance during intervention and results in an actual effect size value $(d)$ that people can understand easier than the numbers obtained from calculations of Percentage of Nonoverlapping Data or Percentage of Reduction measure (Olive \& Smith).

\section{Results}

\section{Minimal Meaningful Benefit and Minimal Meaningful Harm}

None of the participants' communication and organization scores descended below baseline levels (see Figures 1 and 2). This would suggest that there is no harm in using the ELITE intervention. Following baseline data collection it became evident that all participants had high scores related to their perceived use of their communication and organization skills. This would suggest that minimal meaningful benefit would have to be small due to a ceiling effect. As such, we decided that rather than specifying a value to represent minimal meaningful benefit, participants would demonstrate minimal meaningful benefit if scores ascended beyond the highest baseline score during the intervention period, and remained above the highest baseline throughout the intervention into the post intervention period.

\section{$S_{\text {all }}$}

We calculated Standard Mean Difference by subtracting the mean baseline score from the mean interventions score and dividing it by the standard deviation of the baseline scores (Olive \& Smith, 2005). The mean interventions score is the mean of all the intervention scores (communication and organization) and the two post intervention weeks. Readers can find $\mathrm{SMD}_{\text {all }}$ effect sizes for communication and organization in Table 1. Results show that the intervention had the greatest effect for participant Tennis1 followed by Tennis2, Hockey2, Hockey3 and finally Hockey3 who showed the smallest effect.

\section{Table 1 SMDall Effect Size Calculations for Communication Skills and Organization Skills}

\begin{tabular}{lcc}
\hline & SMD $_{\text {all }}$ Communication & SMD $_{\text {all }}$ Organization \\
\hline Hockey1 & $d=.53$ & $d=.23$ \\
Hockey2 & $d=1.7$ & $d=1.69$ \\
Hockey3 & $d=1.48$ & $d=1.03$ \\
Tennis1 & $d=9.62$ & $d=6.04$ \\
Tennis2 & $d=1.76$ & $d=2.35$ \\
\hline
\end{tabular}

Note. $\mathrm{SMD}_{\text {all }}$ refers to Standard Mean Difference for all the baseline and intervention points 


\section{Communication}

A visual analysis of Figure 1 shows that both tennis participants recorded a minimal meaningful benefit of perceived use of communication skills (i.e., intervention and post intervention communication scores remained above the minimal meaningful benefit line). During the communication intervention, participant Tennis 1 scored 10 out of 10 on communication skill use, and then repeated this during post intervention. This increase happened immediately after the communication intervention began; increasing confidence that the changes were a result of the intervention (Hrycaiko \& Martin, 1996). We also observed a clear effect with participant Tennis2. Baseline scores were in the opposite direction to the hypothesized treatment effect, we observed an effect immediately after initiation of treatment, and there were no overlapping data points (Hrycaiko \& Martin).

The hockey participants did not maintain intervention and post intervention communication scores beyond the highest baseline levels. Participant Hockey 2 did demonstrate higher intervention and post intervention scores for all but one baseline score that may suggest that this participant did benefit from the intervention in a trivial not a meaningful way (Stoové \& Andersen, 2003).

\section{Organization}

A visual analysis of Figure 2 shows that both tennis players also demonstrated a minimal meaningful benefit in perceived use of organization skills (i.e., intervention and post intervention organization scores remained above the minimal meaningful benefit line). The baseline scores for both Tennis 1 and Tennis 2 were in the direction of the hypothesized effect, which may reduce confidence that changes are because of the intervention (Hrycaiko \& Martin, 1996). Figure 2 shows that organization scores increased during the time when we implemented the communication intervention; however, because the intervention did not target organization at this point readers can regard this phase as baseline data for organization skills. Relative to the baseline period when participants did not receive treatment, we considered results meaningful because both tennis participants' scores ascended above the highest baseline score recorded in the first six weeks of baseline.

The hockey participants did not maintain intervention and post intervention organization scores beyond the highest baseline levels. Participant Hockey1 showed no effects at all; however, both Hockey2 and Hockey3 showed increases in organization, but we did not consider these increases meaningful because they were lower than the highest baseline scores (which the first author recorded during the communication phase).

\section{Social Validity Interviews}

All participants were interviewed post intervention period and resultant content analysis (Tesch, 1990) of the interviews revealed two main themes related to the intervention; namely, value of the outcomes and enjoyment of procedures. 

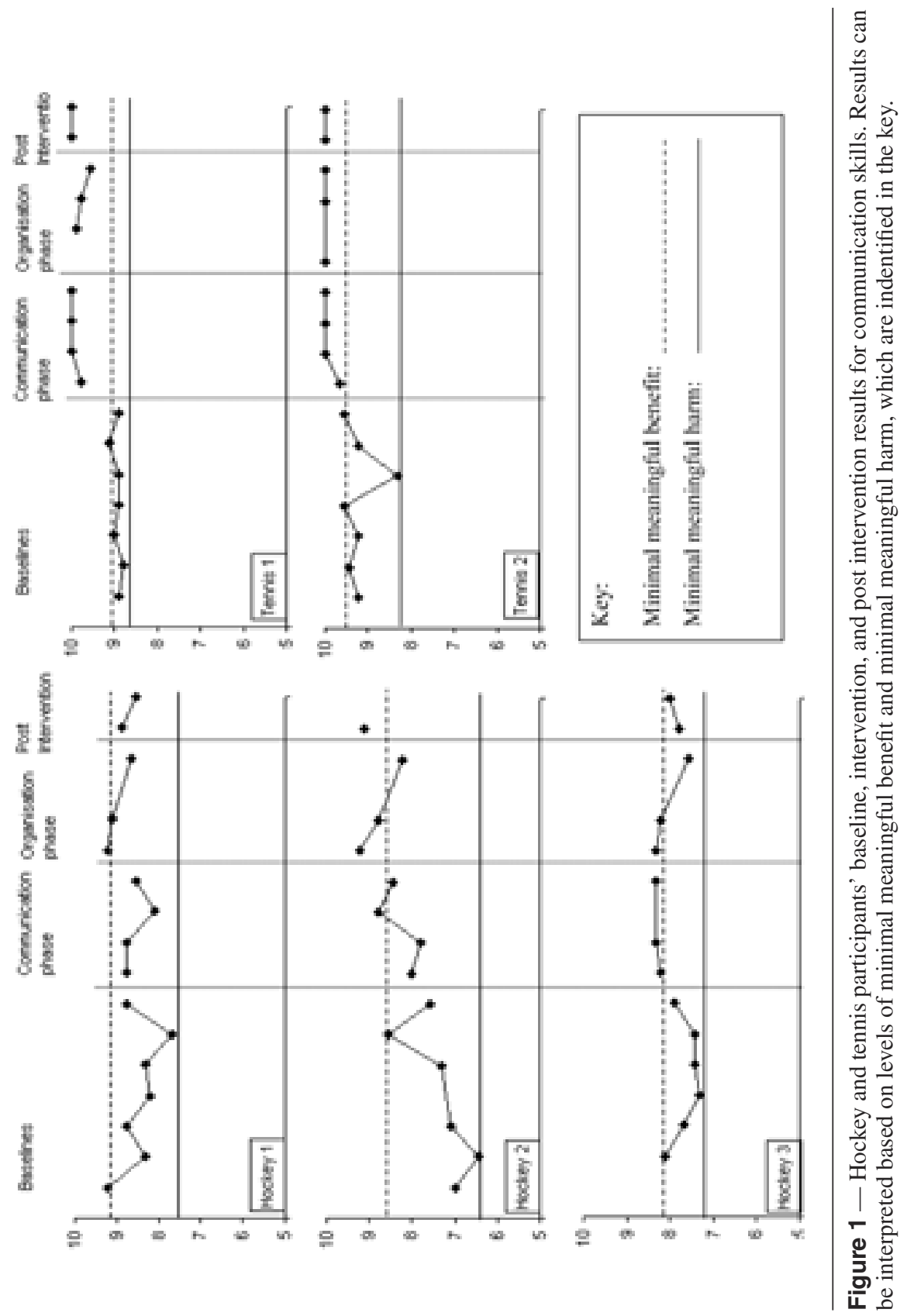


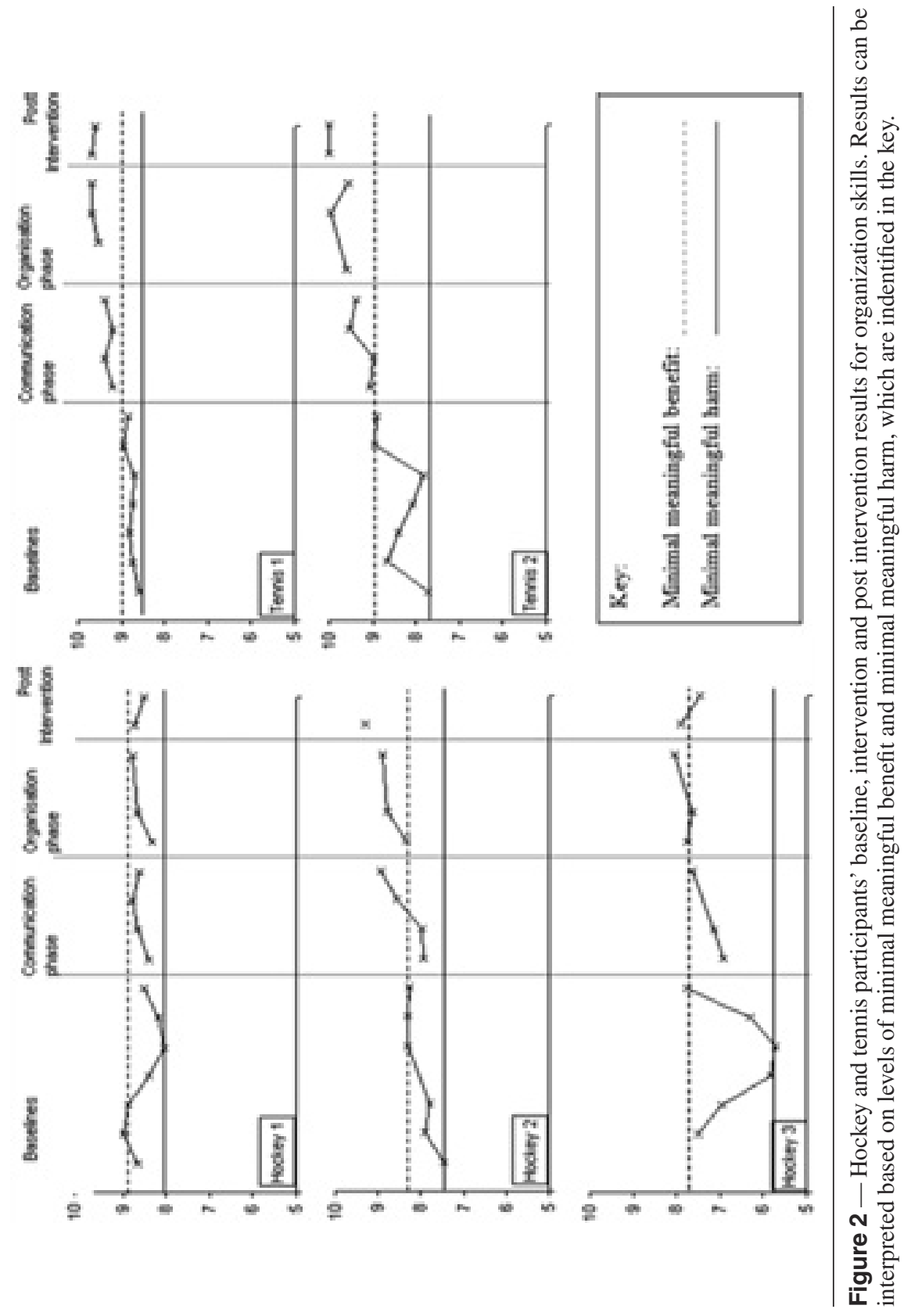


Value. Despite not recording meaningful improvements, the hockey participants did value the intervention. For example, participant Hockey1 said:

We have qualified for the first ever hockey champions league; we won our university gold. We haven't done that in the previous three years. I think that certainly shows that identifying communication and organization is a really big thing. I think we have gone out and shown how important they are.

Participant Hockey2 also valued what he had learned:

I'm much more organized than I was. I've written myself a revision timetable recording all the stuff I'm doing. It even records when I go out and days I've given myself, which I have never done before. I tick it off every day. I have never done that before.

Participant Tennis1 talked about the value of learning communication skills, "I think communication skills are hugely important. Just generally, I think communication is one of the main ways to socialize. If you don't communicate you won't have many friends."

Enjoyment. Participants generally enjoyed participating in the intervention, even though not all of them showed meaningful improvements. For example, participant Hockey 2 discussed the interactive, experiential nature of the ELITE intervention:

When I heard about this intervention, I thought this won't be good because when we played for our different counties we have gone through these kinds of things. But, it was always just put up on a screen. We never do anything about it. You never get to show what you have learned. So, this has been really good.

When asked which parts of the intervention participant Hockey3 enjoyed he responded:

I think the organization parts have been good. I've liked them because they are useful and I can use them. It gave me a couple of ideas of things that I can do better. So, those bits were really good.

Finally, participant Tennis2 discussed the parts of the intervention she enjoyed:

I liked the games, which I wasn't expecting too. I was really worried about them [laughing]. But, that was actually really good. I came out of that feeling really happy; or a lot happier with the communication thing and I felt a lot more confident about it [communication].

These qualitative data revealed that the participants enjoyed the intervention, they valued communication skills and organization skills, and most people felt they left the intervention having learned something. 


\section{Discussion}

The results of this study revealed that researchers and practitioners could use the ELITE intervention as a method of increasing the perceived use of communication and organization skills. The use of two phases of reflective practice, targeting two life skills (communication and organization skills), resulted in meaningful increases in targeted life skills in some participants, but not in others. We might attribute this difference to the types of experiences that the participants had during their sporting lives. Specifically, the hockey players may have already been aware of their life skills because of the interactive nature of this team sport.

In interactive team sports, such as hockey, communication skills are important components of team performances. Indeed, effective communication is a critical element in the success of athletic teams (Sullivan, 1993). Hockey participants may have been aware of the need for effective communication skills because of the nature of the sport. On the other hand, tennis participants might not have been aware of the need for communication for success (even thought they would have undoubtedly engaged their communication skills by playing tennis). As such, the tennis participants may have had more room for improvement because communication was not an area of performance that they had considered before. By participating in the intervention, the tennis players may have considered different types of communication (i.e., with coaches, when playing doubles, when playing team tennis), and scores related to perceived use of communication skills increased.

The results for organization skills were less clear than communication results because of the inability to demonstrate a true baseline and the omission of counterbalancing. During the communication phase of the intervention, some of the participants recorded an increase in organization skills even though these skills were not the focus of the intervention at that time. Filling in the life skills instrument during the baseline period acted as the first phase of reflection for some participants, and some participants began to increase perceived use of the skills they had learned. Similarly, reflecting on communication skills may have influenced one's perceived use of organization skills.

The differences between tennis players and hockey players may be gender related. Specifically, the tennis players were all female and the hockey players were all male. Females have consistently shown higher positive youth development profiles than males (Lerner, 2005; Lerner et al. 2006). Theokas and Lerner (2006) found that females reported higher scores than males on the 5Cs (caring, confidence, compassion character and connection) of positive youth development, and that given the strength and consistency of these gender differences future research should examine findings separately by gender.

Enjoying and valuing the intervention is potentially an important process in developing life skills. Petitpas, Cornelius, Van Raalte, and Jones (2005) proposed that young people with high intrinsic motivation for sport would be more likely to develop positive life skills. Similarly, Larson (2000) suggested that sport was a good context for positive youth development because it is a structured activity where young people choose to participate freely. Finally, Hellison and Walsh (2002) found that having fun and enjoyment was an important process in positive outcomes associated with programs employing the personal-social responsibility model (Hellison, 1978). If young people do not enjoy participating in life skills 
interventions, they may not benefit from a life skills intervention. A strength of the current research is that the participants enjoyed the ELITE intervention.

\section{Limitations and Suggestions for Further Research}

The validation of the 28 -item measure was limited by the small sample size. Therefore, it is not entirely clear whether communication and organization were independent, dependent, or mediating variables. Consequently, one might reveal a correlation with self-report outcome measures administered at the same time due to common method variance. As a result, scholars and practitioners may observe changes before and after intervention but they cannot directly attribute this change to the intervention, as change may have occurred anyway due to unobservable developmental factors. Future rigorous evaluation of the 28 -item measure is therefore required.

The intervention involved athletes interacting in small groups from the same sport. This raises the question of whether the individual athlete was the unit of analysis because athletes within each sport may not be independent, and intervention effects could be influenced by the other athletes in the group. Future research needs to address this issue by analyzing changes in life skill development from both nomothetic and idiographic perspectives. The type of life skill being learned may also affect whether evaluations are nomothetic or idiographic. For example, interpersonal skills, such as communication, may need group based evaluation because they are interpersonal in nature; whereas, organization (and similar intraindividual skills) may not require interaction and are not influenced by other athletes in a group setting and may be better measured with idiographic measures.

Future research using single subject designs needs to consider different ways of measuring life skills during baseline periods that do not encourage reflection and that address issues of potential methods variance. A limitation of the reflective practice procedures of the ELITE intervention was that we based the program on the assumption that young people have positive experiences upon which to reflect. If young people have not had positive experiences, they will not be able to increase their awareness of the skills they have been using. As such, practitioners should use the ELITE intervention as a second phase of life skill development. The first phase should be the structuring of young people's sport programs that give young people a range of skill building activities (e.g., prolonged supportive relationship with peers, coaches and peers in a safe rule bound environment). Practitioners can then use the ELITE intervention to highlight these skills and facilitate the transfer of life skills across life domains.

Future researchers may also consider using different experimental designs to investigate the effectiveness of the intervention. For example, counterbalancing the design, so that one group receives the organization phase first and the other group receives the communication phase first, could help determine the effectiveness of intervention and the extent to which order is influencing the results.

We could not establish whether participants transferred life skills across life domains because we only took self-report measurements in the sporting domain. As such, future research may adopt different measurement tools (e.g., observational data) and integrate measures across life domains into an evaluation package to measure whether participants use life skills in other life domains. A series of interviews at key points during the intervention could also illuminate the process of 
development associated with the intervention and could be part of the intervention to ensure the program procedures are tailored to the individual.

We based the decision to target communication and organization on a series of focus groups to understand which life skills British young people need (e.g., Jones \& Lavallee, 2009). As such, the current version of the ELITE intervention may not be specific to the needs of all young people. Future researchers may wish conduct similar focus groups before treatment to tailor the program to the specific needs of the sample. Establishing the needs of each sample should be the first step of future intervention research.

\section{Implications}

Although scholars and practitioners have not used reflective practice as an exclusive strategy to promote life skills in young people, current findings suggest young people could use reflection in action and reflection on action to develop life skills through sport. Previous research that has used reflective practice as part of a broader regimen of life skills education has produced some evidence to support the use of reflective practice. For example, the personal-social responsibility model (Hellison, 1978) used both anticipatory reflection and reflection on action. Practitioners could actively encourage reflection as a life skills strategy in its own right as well as supplementing other types of life skills education with reflective practice strategies.

To provide young people with positive experiences coaches and practitioners should create a life skills climate where young people are required to demonstrate life skills such as communication and organization in day-to-day training and competition activities. For example, a coach may encourage athletes to talk to one another during scheduled breaks to find a solution to a performance problem. Similarly, coaches may delegate responsibility for warm ups to athletes so they have to both organize the other athletes and communicate the warm up procedures. After executing these skills, coaches and practitioners can encourage reflection so that athletes realize they have used these skills and that these skills are useful in other life domains. Moreover, coaches, practitioners, and athletes can use reflection to evaluate skills and to create plans for better communication and organization in the future. Gould, Collins, Lauer, and Chung (2005) found that a sample of award winning coaches, recognized for their achievements in developing good citizens, productive individuals, and successful athletes, implemented several of the aforementioned strategies. Specifically, Gould et al. found that these award winning coaches did not rely on one strategy or technique; rather, they talked about a continual process of life skill development guided by a philosophical base, trust, and strong coachplayer relationships. In addition, these coaches implemented specific strategies and follow-up procedures for helping their players develop including treating players with respect, teambuilding, utilizing parents, peers, and societal norms.

Coaches and practitioners may also wish to expand their life skills education beyond communication and organization to other potentially pertinent life skills. Other life skills (e.g., respect, initiative, discipline, mastery motivation) could be encouraged by coaches so that young people are required to demonstrate these skills, values, and virtues to be part of the team or training group. Coaches and practitioners could then use the same reflection procedures from the ELITE intervention to show young people that they have knowledge in action and they can use these specific skills in other settings. 


\section{Conclusion}

In conclusion, the findings provide preliminary evidence that scholars and practitioners can use the ELITE intervention to increase young peoples' perceived use of the life skills acquired through sport. The participants valued both communication and organization skills and have been shown to be important youth sport outcomes. The tennis players showed clear and meaningful improvements while some hockey players improved but not in a meaningful way. This may be attributed to the types of experience upon which the participants reflected and the nature of their sporting experiences (i.e., team vs. individual sports, gender). Future research should focus on integrating the ELITE intervention with well-planned sport programs to expose young people to a range of skill building activities.

\section{References}

Arnett, J. (2007). The long and leisurely route: Coming of age in Europe today. Current History (New York, N.Y.), 106, 130-136.

Barlow, D.H., \& Hersen, M. (1984). Single case experimental designs: Strategies for studying behavior change (2nd ed.). New York, NY: Allyn \& Bacon.

Brunelle, J., Danish, S.J., \& Forneris, T. (2007). The impact of a sport based life skills program on adolescent prosocial values. Applied Developmental Science, 11, 43-55.

Collaborative for Academic, Social, and Emotional Learning. (2003). Safe and sound: An educational leader's guide to evidence-based social and emotional learning programs. Chicago: Author.

Coleman, J., \& Roker, D. (1998). Adolescence. The Psychologist, 11, 593-596.

Danish, S.J. (2002). Going for the goal: Leader manual (4th ed.). Richmond, VA: Life Skills Associates.

Danish, S.J., Petitpas, A.L., \& Hale, B.D. (1993). Life development intervention for athletes: Life skills through sports. The Counseling Psychologist, 21, 352-385.

Dworkin, J.B., Larson, R.W., \& Hansen, D. (2003). Adolescents' accounts of growth experiences in youth activities. Journal of Youth and Adolescence, 32, 17-26.

Fox, K., \& Rickards, L. (2004). Sport and Leisure: Results from the sport and leisure module of the 2002 General Household Survey. Retrieved November 19, 2009 from: http:// www.statistics.gov.uk/downloads/theme_compendia/Sport\&Leisure.pdf.

Gould, D., \& Carson, S. (2008). Life skills development through sport: current status and future directions. International Review of Sport \& Exercise Psychology, 1, 58-78.

Gould, D., Collins, K., Lauer, L., \& Chung, Y. (2005). Coaching life skills: A working model. Sport and Exercise Psychology Review, 2, 4-12.

Hansen, D.M., \& Larson, R. (2005). The Youth Experience Survey 2.0: Instrument revisions and validity testing. University of Illinois at Urbana-Champaign, Youth Development Research Project.

Hansen, D.M., Larson, R.W., \& Dworkin, J.B. (2003). What adolescents learn in organised youth activities: A survey of self-reported developmental experiences. Journal of Research on Adolescence, 13, 25-55.

Hellison, D. (1978). Beyond balls and bats: Alienated (and other) youth in the gym. Washington, D.C.: American Association of Health, Physical Education, \& Recreation.

Hellison, D., \& Walsh, D. (2002). Responsibility-based youth programs evaluation: investigating the investigations. Quest, 54, 292-307.

Hrycaiko, D.W., \& Martin, G.L. (1996). Applied research studies with single-subject designs: Why so few? Journal of Applied Sport Psychology, 8, 183-199.

Johnson, J.J.M., Hrycaiko, D.W., Johnson, G.V., \& Halas, J.M. (2004). Self-talk and female youth soccer performance. The Sport Psychologist, 18, 44-59. 
Jones, M.I., \& Lavallee, D. (2009). Exploring the life skills needs of adolescent athletes. Psychology of Sport and Exercise, 10, 159-167.

Larson, R.W. (2000). Toward a psychology of positive youth development. The American Psychologist, 55, 170-183.

Larson, R.W., Hansen, D., \& Moneta, G. (2006). Differing profiles of developmental experiences across types of organized youth activities. Developmental Psychology, 42, 849-863.

Lerner, R.M. (2005, September). Promoting Positive Youth Development: Theoretical and Empirical Bases. White paper prepared for the Workshop on the Science of Adolescent Health and Development, National Research Council/Institute of Medicine. Washington D.C.: National Academies of Science.

Lerner, R.M., Lerner, J.V., Almerigi, J., Theokas, C., Phelps, E., Naudeau, S., et al. (2006). Toward a new vision and vocabulary about adolescence: Theoretical and empirical bases of a "positive youth development" perspective. In L. Balter \& C.S. Tamis-LeMonda (Eds.), Child psychology: A handbook of contemporary issues (pp. 445-469). New York: Taylor \& Francis.

National Center for Chronic Disease Prevention and Health Promotion. (2007). Healthy youth. Retrieved January 20, 2010, from http://www.cdc.gov/HealthyYouth/SHER/ standards/4.htm.

Olive, M.L., \& Smith, B.W. (2005). Effect size calculations and single subject designs. Educational Psychology, 25, 313-324.

Papacharisis, V., Goudas, M., Danish, S., \& Theodorakis, Y. (2005). The effectiveness of teaching a life skills program in a school-based sport context. Journal of Applied Sport Psychology, 3, 247-254.

Petitpas, A.J., Cornelius, A.E., Van Raalte, J.L., \& Jones, T. (2005). A framework for planning youth sport programs that foster psychosocial development. The Sport Psychologist, 19, 63-80.

Petrie, T.A., \& Denson, E.L. (2003). A student-athlete's guide to college success: Peak performance in class and life. Belmont, CA: Wadsworth/Thomson Learing.

Rogge, J. (2004). IOC and UNAIDS Join Forces to Engage Sport Community in Fight Against Aids. IOC Press Release, 1 June.

Schön, D. (1987). Educating the reflective practitioner. San Francisco: Jossey-Bass.

Stoové, M.A., \& Andersen, M.B. (2003). What are we looking at, and how big is it? Physical Therapy in Sport, 4, 93-97.

Sullivan, P.A. (1993). Communication skills training for interactive sports. The Sport Psychologist, 7, 79-91.

Tesch, R. (1990). Qualitative research: Analysis types and software tools. London: The Falmer Press.

Theokas, C., \& Lerner, R.M. (2006). Observed ecological assets in families, schools, and neighborhoods: Conceptualization, measurement and relations with positive and negative developmental outcomes. Applied Developmental Science, 10, 61-74.

United Nations. (2005). World youth report 2005: Young people today and in 2015. United Nations, Department of Economic and Social Affairs.

Van Manen, M. (1999). The practice of practice. In M. Lange, J. Olson, H. Hansen, \& W. Bÿnder (eds.), Changing schools/changing practices: Perspectives on educational reform and teacher professionalism. Luvain, Belgium: Garant. Retrieved August 2, 2007 from http://www.phenomenologyonline.com/max/articles/practice.html.

Von Korff, M., Jensen, M.P., \& Karoly, P. (2000). Assessing global pain severity by selfreport in clinical and health services research. Spine, 25, 3140-3151.

Wolf, M. (1978). Social validity: The case for subjective measurement of how applied behavior analysis is finding its heart. Journal of Applied Behavior Analysis, 11, 203-214. 